\title{
The Sublime and Human Creations
}

\author{
Brendan McShane \\ Student/Laurentian University/Sudbury, Ontario, Canada \\ Correspondence: bmcshane@laurentian.ca
}

Acknowledgements: Brendan McShane would like to thank the reviewers of this article for their thorough feedback. Their critical contributions improved both the form and content of the article, and aided in the removal of its dead weight.

Abstract: Immanuel Kant pre-emptively excludes all man-made contrivances from his definition of the sublime. The limitations of human creation and the purposiveness in its design preclude it from consideration from both mathematical and dynamic sublimity. At best, human creation is "secondorder" or "impurely" sublime. This paper thoroughly considers this assertion and searches for possible exceptions, both hypothetical and extant. It implies that humankind may be a nearing a point where it is able to create a pure example of the sublime, as defined by Kant.

According to Immanuel Kant, the sublime is an aesthetic experience in which a person is impacted by both a feeling of intimidation and a form of pleasure. Kant considers sublimity to be principally evoked from experiences of immensity exhibited within the natural world ("crude nature" as Kant calls it), as in cases of human-made creations, "both the form and magnitude are determined by a human purpose" (Kant 109; ch. 26, para. 6). As human creations must be wholly perceivable by both a person's imagination and reason, they are not truly sublime. This may not always the case: numerous creations from human sciences and arts could be plausible examples of phenomena that can induce the sublime experience. It is important to note, however, that Kant considers sublimity to have a moral importance, as the sublime highlights human freedom in contrast to the immensity of the natural world during this experience. Due to this importance, we will need to look for cases of human fabrications that exhibit more than just great immensity if we are to discover truly Kantian examples of human-made sublimity. This is a tall order, as the criteria Kant describes for sublimity is stringent (and will be described thoroughly below), yet I will attempt to illustrate the strongest possible examples of human creations that could evoke the sublime and the respective solutions as to how they can achieve this. This article will be an example of one of the most enjoyable practices in philosophy: attempting to solve a philosophical issue that greater minds have deemed potentially impossible. Although I may not be able to definitively provide cases or explanations of the human-made Kantian sublime, I will give it the old college try. Hopefully, it will illuminate the cracks and crevices in Kant's aesthetics that allow for more than he intended, and will at the very least be an exemplary instance of the manner in which old debates can be dissected at new angles.

Before an exploration of the possibility of human creations evoking the sublime can be properly examined, a thoroughly adequate and serviceable, yet concise, overview of Kant's detailing of the sublime should be presented. Stanford University's online Encyclopedia of Philosophy provides a succinct description of the Kantian sublime experience: while witnessing a natural phenomenon of immense proportions, we encounter "a feeling of the superiority of our own power 
of reason, as a supersensible faculty, over nature" (Ginsberg). These experiences of the sublime are both pleasurable, with the feeling of the triumph of reason, and unpleasant, with the feeling of the inadequacy of human capacities like imagination (Ginsberg). Kant expounds upon the sublime experience in his text Critique of Aesthetic Judgement, the first Division in his larger work Critique of Judgement. The sublime, in a similar respect to that of the Kantian notion of beauty, is based neither on sensations nor determinate concepts, but on a judgement of reflection (Kant 97; ch. 23, para. 1). Judgements of the sublime entail a certain sort of pleasurable feeling which is singular, yet "nonetheless proclaim themselves universally valid for all subjects" (97; ch. 23, para. 1). This is the first major criterion for candidates evoking sublimity: they should be universally evocative to all who witness them. Unlike judgements of beauty, however, which are connected to the form of a thing and are therefore "bounded", the sublime experience is triggered by the formless and is thus "boundless" (98; ch. 23 para. 2). The mind, having an evocation of boundlessness, experiences a "negative pleasure", as "the mind is not just attracted to the object but is alternately always repelled as well" (98; ch. 23, para. 2). That which could evoke such a negative pleasure in the mind can be more readily comprehended by the two categories of sublimity that Kant provides. The first category is that of the mathematically sublime. The mathematically sublime is evoked from that which is of great magnitude, and involves the conception of that which is "large beyond all other comparison" (Kant 103; ch. 25, para. 1). Contrary to his implication that sublimity is derived from non-human phenomena, Kant actually uses examples of human structures to illustrate the manner in which mathematical sublimity functions (this already appears to weaken this distinction about the sublime, but to be charitable to Kant, they can be viewed as examples for ease of clarity rather than accuracy). To characterize the sublime experience, Kant discusses the pleasure of entering St. Peter's Basilica for the first time, and the subsequent feeling that the "the imagination is inadequate for exhibiting the idea of the whole" (108, 109; ch. 26, para. 4). Kant does however provide natural examples in which the mathematically sublime can be experienced; he states that a large tree can stimulate such an effect. A large tree can act as a standard of measurement to conceive of a mountain, and a mountain for the Earth's diameter, and the Earth for the galaxy, and finally the galaxy to the system beyond (Kant 113; ch. 26, para. 12). Therefore, witnessing one thing of great magnitude can evoke that of perceivably limitless magnitude beyond human imagining; such is the mathematically sublime experience. The second category of the sublime experience is that of the dynamically sublime. The dynamically sublime is invoked by that exhibiting great "might", or "dominance" when it exhibits might beyond all possible resistance (Kant 119; ch. 28, para. 1). When an aesthetic judgment is made in the presence of such an event, "we consider nature as a might that has no dominance over us"; this is the dynamically sublime (Kant 119; ch. 28, para. 1). Relevant naturally occurring phenomena are "lightning and thunderclaps, volcanoes with all their destructive power, hurricanes with all the devastation they leave behind", and the like (Kant 120; ch. 28, para. 5). Although these marvels can indeed cause humans harm, simply witnessing them can provide a particular sort of pleasure. Kant states that such phenomena "raise the soul's fortitude above its usual middle range" and "gives us the courage [to believe] that we could be a match for nature's seeming omnipotence" (120; ch. 28, para. 5). In this way, a second major criterion can be identified, as the catalyst for sublimity should not just be large or forceful, but should evoke a size or force that is boundless. What though could provide such magnitude or force that it would allow one to have such inspirational experiences, being beyond human imagination but within reason, and yet still made by human hands? To effectively demonstrate the possibility that human creations could be the basis for the sublime experience, examples that would validly fit within both of Kant's presented categories will be explored.

The most prominent issue with identifying cases of Kantian sublimity by way of human creations is that of their intentionality. Uygar Abaci, in his article "Kant's Justified Dismissal of Artistic 
Sublimity", addresses this problem explicitly. As Kant characterizes the sublime experience as being induced through witnessing raw nature, as, unlike human creations made for a purpose, raw nature is "nonpurposive" or "contrapurposive"; it exists without the design or intentions of organic beings (Abaci pt. II, para. 5). Abaci identifies that human-made works contain "teleological elements that determine the form and the magnitude of the object", such as an artist's intentions and presented themes (pt. II, para. 5). In this way, even if a fabrication can evoke a synonymously sublime experience to those that are provided within nature, the sublimity is an "impure" case (Abaci pt. II, para. 5). Although sublimity is that which is experienced in the mind and is not a quality of an object or event, Abaci notes that sublime experiences should not be understood "in isolation from the broader context to which they belong"; namely, pure sublimity is dependent on raw nature (pt. I, para. 6). By way of an analogy, pottery may only purely be considered as being of a certain (hypothetical) style if it is crafted upon a particular type of pottery wheel. Even if a pot was crafted to the specifications of that style (say, the particular size, form, and composition), but was not crafted upon the necessitated pottery wheel, it would not be truly be considered an object exhibiting the discussed style, despite the pot being materially identical to those that exemplify it. This could be the inescapable dilemma for those wishing to find "pure sublimity" derived from human creations (that which lies outside of a particular definition cannot truly be within it), but that does not mean that impure cases that are otherwise of identical character cannot be readily discovered. For instance, Abaci himself admits (though he deems the possibility unlikely) that viewing a painting of an immense mountain could lead the mind to imagine the effect of actually viewing such a mountain with one's own eyes, leading to a mathematically sublime experience (Abaci pt. V, para. 3). This could be understood as similar to the "suspension of disbelief" that audiences often undertake when watching a film or theatrical piece. In this way, as sublimity is solely a mental occurrence, one can experience an identical sublimity to that of an actual mountain, even if such an experience is of a "second-order" (Abaci pt. V, para. 3). Although the mental experience may be largely identical, this sort of sublimity certainly is impure by Kantian standards as it is filtered through an obviously human-made filter (the painting). Purer examples will have to be discovered if the possibility of human-created sublimity is to be considered valid, so the following paragraphs will attempt to propose a series of more likely candidates.

Now that Kant's notion of the sublime, and its relevant issues, has been provided, strong candidates of human creations that stimulate this experience can be discussed. The first thing to look for as potential candidates would be those of sufficient size to elicit a sense of wonder from viewers. Impressive architecture is the most obvious candidate, and (as mentioned previously) is used by Kant to exemplify the mathematical sublime. Although most structures would not qualify as conducive to the sublime experience, there are many that would rival the immensity of natural phenomena: bridges that cross wide rivers, skyscrapers taller than clifftops, and mine shafts deeper than ravines. Possibly the clearest example of such a structure would be the $\mathrm{CN}$ Tower, as few people can stand on its glass floor without feeling awe and intimidation while looking down. Additionally, such buildings provide the same allowance for a person to use their faculty of reason, while being unable for their imagination to keep pace. For example, one is able to accept cognitively that a grand mansion was built with certain thousand nails, but to imagine the total sum of all of the individual nails would be beyond the capacity of imagination. However, although impressive architecture meets the superficial criteria that Kant provides for the mathematically sublime experience (namely, breathtaking immensity and reason outpacing imagination), central aspects of the experience are not present in this example. Though such structures provide the mathematical magnitude reminiscent of the sublime and may do so universally for all who witness them, the witnesses nonetheless consciously know that these are not natural formations. The CN Tower, while rivaling the height of mountains, is obviously human-made, and therefore does not allow the necessary contrast of human freedom to raw nature that is so 
important to Kant. In this way, architecture is possibly the most prevalent of the candidates for human-made sublimity, but also the least pure. Put simply, architecture can be a brilliant counterfeit of the mathematically sublime, but we will need to continue to look elsewhere for purer examples.

Perhaps effective examples of sublimity can be found in more recent examples of human ingenuity, as Kant passed away long before the impressive technological achievements of the last century. One such example is a rocket ship, as it demonstrates both mathematical and dynamical immensity. The mathematical immensity of a rocket ship can be experienced from its great height; for instance, the Block 1 system of NASA's developing Space Launch System is 322 feet tall, which is "higher than the Statue of Liberty" (NASA 2). If one were to stand at this rocket's base, the immensity of its height would rival many imposing natural formations that could be witnessed, such as tall waterfalls or glaciers. Furthermore, this tremendous physical trait strongly suggests the inducement of sublimity, as a person can easily identify the number of feet that is this rocket's height through the use of reason, but it is unlikely that anyone can envision every inch of it in their imagination simultaneously. This rocket ship also demonstrates a great magnitude of dynamical force, as "it will produce 8.8 million pounds of thrust at liftoff, equivalent to more than 160,000 Corvette engines" (NASA 2). Although volcanic eruptions and geysers are usually the sorts of dynamical forces that Kant considers as evoking the sublime, the Space Launch System demonstrates even greater might. While eruptions and geysers are powerful enough to oppose the downward force of gravity temporarily, this rocket has the might to entirely overcome it. Witnessing such might certainly would elicit the wonder and stupefaction that is characteristic of the sublime, such as the 1969 launch of the Apollo 11 rocket, which is a popular cultural touchstone of people's awe in witnessing the power of a launching rocket. Another event in which emerging technology famously evoked a similar feeling was the first successful testing of an atomic bomb. The physicist Robert J. Oppenheimer, while observing the explosion, was so moved by it as to be reminded of lines from the Hindu epic, Bhagavad-Gita:

"If the radiance of a thousand suns

Were to burst at once into the sky,

That would be like the splendor

$$
\text { of the Mighty One... }
$$

I am become Death,

The shatterer of worlds." (Lamont 235)

Such a response, reminding Oppenheimer of a passage describing divine power, strongly suggests the sublime experience of shock and profundity. Although Kant disparages the notion that human creations can result in the sublime, it is altogether unsurprising that the atomic bomb might induce the sublime experience, as its dynamical magnitude puts any occurrence of the sublimity that Kant could have witnessed to shame. The dynamical force of this explosion was such that the "pressure, caving in the ground beneath, was over 100 billion atmospheres, the most ever to occur at the earth's surface" (Kant 236). Due to these facts about rocket ships and atomic bombs, the notion that viewing them could evoke wonder is not questionable, but the true question is whether these examples meet the other Kantian criteria agreeably. It may be difficult to attest that they do, as anyone who sees a rocket take off or a bomb test would be aware of the purposiveness of such an event. There is however a partial solution that may soften the knowledge of purposiveness in such a case. Although every person observing these events experiences the sublime individually, the combined cognitive capacities of a great many people are required to create such a circumstance. In the case of the atomic 
bomb, numerous engineers, military personnel, and physicists necessitated the completion of the project. In this way, even if the specific capacities of a single person are unable to lead to the incitement of the sublime experience, their cooperated capacities may. In turn, each can undergo sublimity individually once their efforts reach fruition. The issue of purposiveness is still present, as all of the creators of an atomic bomb or a rocket ship are aware that it is a chosen human endeavour, but this can be negated to a certain degree. Although those involved are aware of the purpose of the project as a whole, and are aware of their specific purpose within the project (for example, designing the fins on the lower end of a rocket), they remain unaware of all the other particular purposes that go into such a creation. In this way, such projects can provide a "purer" sublimity than that of other fabrications; for instance, an atomic bomb presents more purposive ambiguity in its details than the construction of an elegant piece of furniture. In addition, such as in the case of Oppenheimer, even minds of the greatest capacity can have their knowledge of the design and intention of such projects temporarily dispelled while in the presence of sufficiently immense magnitude or force.

If, however, this last solution seems unsatisfactory, that is unsurprising. Certainly the purposiveness exhibited by the entirety of a rocket ship is lessened when one does not know every purpose that went into its construction, but the presence of purposiveness remains apparent overall. Metaphorically, the fingerprint of human intention may be smudged, but it is visible nonetheless. However, the example of the atomic bomb could provide a more effective solution in another way. This could be illustrated by a scene in Empire of the Sun. The protagonist, due to his youth and great distance from the bombsite, is initially unaware that the explosion of an atomic bomb is human-made. He views it as an intensely spiritual occurrence. This illustrates that ignorance could be a way around the issue of purposiveness. This possible solution can be exemplified clearly with the following anecdote. A person is walking through the wilderness, and stumbles upon a vast arrangement of stones which, upon viewing it, evokes a mathematically sublime experience. If this person was to continue walking for another hour and meet a person who informed them that the arrangement was not naturally occurring, but was in fact an elaborate rock garden, would the previous sublimity be retroactively invalidated? It would not appear so; the experience at that time was genuine, even if it was contingent on the person's ignorance of the purposive nature of the stones. In both these examples, ignorance opens up a space for human-made sublimity, but the issue then becomes universality. For Kant, the sublime experience should be universal, but the explosion and rock garden would only evoke sublimity for the select few who are unaware of the facts. This does weaken the ability of ignorance to allow pure sublimity, yet this issue can be identified to some degree even within experiences that Kant would likely attest evoke the sublime. For instance, Kant may say that an enormous mountain is a natural formation that would provide the mathematical sublime experience universally. However, one could argue that this is also conditional, as the mountain could only provide this opportunity if viewed from a certain distance or angle, if there is no impeding fog or precipitation, and if one is not deficiently nearsighted or blind. It may be universal, but it is only universal if certain conditions are met (comparable conditions can be imagined for nearly all potentially sublime experiences). In this manner, perhaps ignorance could be one such condition. However, Kant could respond that, because the importance of the sublime is in its pronouncement of human freedom in contrast to the powers of nature, ignorance should not be a central feature of the experience. I would be willing to concede to this point, so although ignorance provides a valid entryway for human creations to evoke the sublime, more agreeable solutions should also be considered.

The medium that may get us closest to the mark in discovering cases of human-made sublimity is video games. Although video games may not intuitively provide the sorts of immensity that is characteristic of the sublime, there are a couple strong candidates. One example is the Call of Duty 
series. An article published by The Washington Post stated that if every hour gamers have played Call of Duty was added up (in only a period of six years) its total play time would greatly exceed that of all human history (Fung). This is an effective example of mathematical enormity, as not only does it represent a number greater than human imagination is able to realize, but it represents a number that is greater than the entire human experience. Another relevant video game example is that of Minecraft, the building simulator. According to the technology magazine Wired, the total size of the world of Minecraft is four billion square kilometres (Fallon). This figure may already suggest sublimity, as it is a number well beyond that which the imagination can conceive, but to further emphasize this magnitude, this article draws a comparison to the Earth's total surface: five-hundred million square kilometres (Fallon). This is a metaphoric drop in the bucket next to the immensity of Minecraft's surface area. Another solution to the problematic issue of humans creating experiences beyond their imaginative capacity can be identified in this latter example. In the case of Minecraft, and similar video games, programmers do not code every feature of the enormous landscape that players can explore. The programmers code algorithms that allow the landscape to self-generate as the players push its boundaries. Metaphorically, video game developers cannot plant a huge oak with their bare hands, but they can plant an acorn, which in turn grows into a sizable tree; in the case of Minecraft, this tree rapidly seeds a near limitless forest. In this manner, a human need not wholly imagine what they are creating. Artificers need only make a template with which their creation can expand off of to produce something beyond imagination. The problematic element of purposiveness can also be addressed in this way; though there is undoubtedly intentionality behind the creation of such templates, the results that these templates produce are not specifically chosen. Although we may have found a purer example of the sublime, as human purposiveness is less impactful than any of the preceding examples, Abaci would likely respond that there is still an issue present. The world of Minecraft may be in a sense evocative of the sublime and "naturally occurring", but it is viewed in the "second order" like a painting. This world may more adequately address the Kantian criterion of purposiveness, but it can only be viewed through a monitor, which gives away the human purposiveness. So we are able to get near the goal, but can only see the goal line through a window that could invalidate the experience in Kant's eyes.

So far, several varieties of human creations have been explored, and although they are able to meet different criteria for the possibility of a sublime experience, none have been able to achieve a maximized level of purity. If, however, a creation were to synthesize these partial solutions, then that creation might meet the mark. I must admit though that I cannot think of anything yet made by human hands that could achieve this, but that does not mean that it is impossible. Now we have a clearer idea of what to look for, and when fact currently fails us we can turn to fiction for an example. Kurt Vonnegut's novel Cat's Cradle provides a substance of human design that incites immense dynamical power, can be universally viewed, and acts as a template for natural forces to proceed well beyond the purview of human purposiveness. It is called "ice-nine". Ice-nine is explained as "a seed", a fabricated grain of ice that instructs the atoms of water it touches to rearrange into a new crystalline structure with a much higher melting point (Vonnegut 45, 46). In this way, one grain of ice-nine would make all water it interacts with turn into unfreezing ice. If a grain gets into the water table, it would cause a chain reaction that would freeze all the oceans and turn all precipitation to hail. Of course, within the plot of Cat's Cradle, this occurs. The subsequent effect is described thusly:

I opened my eyes - and all the sea was ice-nine.

The moist green earth was blue-white pearl.

The sky darkened. Borasisi, the sun, became a sickly yellow ball, tiny and cruel. 
The sky was filled with worms. The worms were tornadoes. (Vonnegut 261)

Similarly to the passage quoted by Oppenheimer, this description certainly sounds like the awe experienced during the sublime experience, yet it meets the specific Kantian criteria more sufficiently. Not only is the dynamical force on a greater scale than the atomic bomb (encompassing the whole earth), but the experience is notably more universal. A scientifically literate person may be able to differentiate an atomic blast from other natural phenomena, but the spread of ice-nine causes natural forces to be indistinguishable from the human creation; they become one and the same. In this way, human purposiveness impacts all the natural forces, but it is the natural forces themselves that evoke sublimity, not the fabricated grain. Therefore, the moral core of the sublime for Kant, human freedom being highlighted against the vast forces of nature, can be present despite the human interference. Furthermore, unlike Minecraft, the results of such a template do not have to be viewed in the "second order" through a screen, but are witnessed with the naked eye. Unfortunately (or perhaps fortunately, for the welfare of terrestrial life), ice-nine is a work of fiction, but it does illustrate the purest manner in which a human creation could illicit a truly Kantian sublime experience.

Now that numerous examples of human creations potentially evoking the sublime have been explored, I would admit that I have achieved only a partial success in arguing their validity. It goes without saying that human creations can induce wonder, intimidation, and awe, but the best I have been able to demonstrate definitively beyond that is that they can induce an impure sublimity in Kantian terms. However, I think the latter examples illustrate that such sublimity can become everincreasingly pure with newer technologies. The doorway to the human-made sublime may only be fractionally ajar at this time, but it appears to be opening rather than closing. We should keep an eye out for what might walk though: it may still be possible to discover a human creation that presents the opportunity for a purely Kantian experience of the sublime. Whether we are trying to or not, we are getting nearer to realizing this.

\section{Works Cited}

“Space Launch System: Building America’s New Rocket for Deep Space Exploration”. National Aeronautics and Space Administration, 4 February 2016, https://www.nasa.gov/sites/default/files/atoms/files/sls october 2015 fact sheet.pdf

Abaci, Uygar. "Kant's Justified Dismissal of the Artistic Sublime". The Journal of Aesthetics and Art Criticism, vol. 66, no. 3 Summer 2008, pp. 237-251. http://www.jstor.org/stable/pdf/40206342.pdf?refreqid=excelsior:4e104078039e8370bc5fe $\underline{\mathrm{fb} 485308 \mathrm{dba}}$

Fallon, Sarah. "How Big is Minecraft? Really, Really, Really Big”. Wired, 27 May 2015, https://www.wired.com/2015/05/data-effect-minecraft/

Fung, Brian. "Humankind has now spent more time playing Call of Duty than it has existed on Earth". The Washington Post, 13 August 2013, https://www.washingtonpost.com/news/theswitch/wp/2013/08/13/humankind-has-now-spent-more-time-playing-call-of-duty-than-ithas-existed-on-earth/?utm term=.bcd66aa46312

Ginsberg, Hannah. "Kant's Aesthetics and Teleology". Stanford Encyclopedia of Philosophy, 13 February 2013, https://plato.stanford.edu/entries/kant-aesthetics/\#2.7

Kant, Immanuel. Critique of Judgement. Translated by Werner S. Pluhar, Hackett Publishing Co., 1987. Lamont, Lansing. Day of Trinity. McClelland and Steward Ltd., 1985.

Vonnegut, Kurt. Cat's Cradle. Random House, Inc., 1991. 